\title{
Quantifying avoidance-related behaviour and bleeding times of sheep of different ages, sex and breeds slaughtered at a municipal and a commercial abattoirs
}

\author{
Y.Z. Njisane \& V. Muchenje ${ }^{\#}$ \\ Department of Livestock and Pasture Science, University of Fort Hare, P. Bag X1314, Alice 5700, South Africa
}

(Received 10 October 2012; Accepted 16 November 2012; First published online 5 July 2013)

Copyright resides with the authors in terms of the Creative Commons Attribution 2.5 South African Licence.

See: http://creativecommons.org/licenses/by/2.5/za/

Condition of use: The user may copy, distribute, transmit and adapt the work, but must recognise the authors and the South African Journal of Animal Science

\begin{abstract}
The effect of abattoir type, age, sheep breed and sex on avoidance-related behaviour and bleeding times at slaughter were determined. Castrates and ewes of different age groups and breeds were used. From the commercial abattoir, 90 castrates and 110 ewes were used while 66 castrates and 19 ewes were obtained from the municipal abattoir. Avoidance-related behaviour and bleeding times differed with abattoir type and age classes. Animals slaughtered at the commercial abattoir were calmer and had shorter bleeding times (61 $\pm 1.16 \mathrm{~s}$ ) than those slaughtered at the municipal abattoir which had a mean bleeding time of $74.2 \pm 2.11 \mathrm{~s}$. Older animals were calmer and had longer bleeding times $(67.5 \pm 1.82 \mathrm{~s})$ than the younger animals which had a mean bleeding time of $61.6 \pm 2.64 \mathrm{~s}$. Avoidance-related behaviour also differed with breed and the sex of the animals with Merino and Dorper + Merino crosses being the calmer than the pure Dorper breed. About $95 \%$ of ewes were calmer than the castrates. It can be concluded that abattoir type, age, breed and sex have an effect on animal behaviour at slaughter. Only abattoir type and sex had an effect on bleeding times.
\end{abstract}

Keywords: Abattoir type, animal handling, bleeding processes, Dorper, Merino, stunning

${ }^{\#}$ Corresponding author: vmuchenje@ufh.ac.za

\section{Introduction}

There are different types and classes of abattoirs, and the abattoir classifications depend on the type of the species slaughtered, abattoir structure and the management system practised. Despite these differences, abattoirs function under the same standard laws and regulations to ensure public health safety. The laws governing abattoir operations include The Meat Act, 2000, and the Animal Protection Act, 1962 and 1935 for animal welfare maintenance (RMAA, 2011).

It has been reported that commercial abattoirs spend more on getting reliable and sophisticated machinery (Gregory, 2005) while most municipal abattoirs in rural areas have poor handling facilities (Ndou et al., 2010). These differences are thought to have an effect on animal welfare thus affecting animal behaviour at slaughter and the quality of the product. Grandin (1999) reported that animals' reactions differ with different handling techniques and systems, including the animal's previous exposure at farms.

Environment changes from the farm to the slaughter house. Lack of control in a particular environment may be stressful to the animals resulting in eccentric behaviour (Broom \& Frazer, 2007). Behaviours such as avoidance and approach can be used to measure aversive handling effects (Boivin et al., 1997; Dodzi \& Muchenje, 2011). In addition, several other factors such as the age, gender, breed, and species of the animal affect animal behaviour (Hansen et al., 2001). Poor welfare conditions also affect the animal's behaviour (Knowles, 1998). 
Abattoir operations at slaughter also affect bleeding efficiency during exsanguination. Two bleeding processes are used in different abattoirs. These are vertical bleeding which renders hygienic conditions, and horizontal bleeding which promotes faster bleeding rates (RMAA, 2011). Literature on general animal behaviour at slaughter from other parts of the world is available (Grandin, 2006; Bourguet et al., 2011). There is a dearth of information on such work under practical conditions, especially in the developing world. The aim of this study was therefore to quantify avoidance-related behaviour and bleeding times of sheep slaughtered at a municipal and a commercial abattoir.

\section{Materials and Methods}

The study was conducted at the East London (EL) commercial and the Adelaide municipal (MA) abattoirs in the Eastern Cape Province, South Africa. Information on the sheep was recorded as the animals came in for slaughter from different farms located in the province. Castrates and ewes from Dorper, Merino and their crosses and of different age groups ( $<10$ months, 11 - 12 months, $>12$ months) were used in the study. From the commercial abattoir, 90 castrates and 110 ewes were obtained while 66 castrates and 19 ewes were obtained from the municipal abattoir. The sheep slaughtered at the EL were brought into the abattoir a day before slaughter by trucks and were put into abattoir holding pens overnight with access to water but with no food. Those slaughtered at the MA were sourced from nearby farms $(20-30 \mathrm{~km})$ and brought in the morning of slaughter; transported in small vans.

Behaviour observations were done before stunning while introducing the animals to the slaughter floor (Terlouw \& Porcher, 2005; Table 1), with higher scores for higher levels of avoidance behaviour. One person standing 1.5 meters away from the exsanguination point was responsible for taking down the records.

Table 1 Avoidance-related behaviour scores of sheep at slaughter before stunning on introduction to the slaughter floor

\begin{tabular}{ll}
\hline Category & Code \\
\hline Standing (rests on four legs) - Mostly calm & 1 \\
Sitting (rests on thighs and front legs) - Calm but threatened & 2 \\
Other e.g. jumping (unstable/trying to escape) - Aggression & 3 \\
\hline Modified from Terlouw \& Porcher (2005). &
\end{tabular}

Animals slaughtered at the EL were introduced from the holding pens onto the slaughter floor using a conveyer restrainer with minimal contact with handlers. Those from the MA were manually driven onto the slaughter floor by the abattoir workers. Electrical stunning was used in both abattoirs. However; the EL used $110 \mathrm{~V}(0.6 \mathrm{~A})$ for 60 seconds and the same person conducted this procedure on the sides of the head above eye level. The MA used $650 \mathrm{~V}$ and several workers conducted the stunning procedure depending on who was available. A horizontal bleeding process was used at the EL. The animals were then hung vertically on a moving rail using their right hind legs. The MA used the vertical bleeding process with the animals hung vertically using both hind legs. Bleeding time was recorded according to the procedure by Kirton \& Woods (1977). The recorded time interval was the one between the start of blood flow and the time the flow changed from a constant stream into drips.

The data was analysed in Genstat (2008) using the main effects model. The $\chi^{2}$ (chi square) test was used to assess the effect of abattoir type, age group, breed, and sex on behavioural scores. Analysis of variance (ANOVA) was used to test the effect of the abattoir type, breed, age group and sex on bleeding times at exsanguination. Interactions between abattoir type, age, breed and sex were also determined.

\section{Results and Discussion}

At the EL there were no differences in sheep behaviour at slaughter, while there were behavioural differences in those that were slaughtered at the MA (Figure 1a). The uniform behaviour observed at the EL 
may be attributed to the improved technologies and quality in management practices at the abattoir. The use of a restrain conveyer on introducing the animals to the slaughter floor encouraged the animals to display a standing posture which in this study was associated with calmness. In addition, these sheep had rested overnight before being slaughtered the following day, thereby getting used to the novel abattoir environment and getting used to social stress. In contrast, the sheep slaughtered at the MA with minimal resting time, and where the manual procedures were used, demonstrated some restlessness (aggression). Ndou et al. (2010) reported that low-throughput abattoirs operate under less friendly conditions with poor handling facilities and less experienced handlers. Most of the animals (37\%) slaughtered at MA showed signs of aggression and/or panic. According to Gonyou (1997), sheep’s primary defence is to flee/charge if they are cornered.

The three genotypes were generally calm (Figure 1b). A relatively large percentage $(20.7 \%)$ of the Dorper were observed to display the aggression/panic associated behaviour "jumping" on introduction to the slaughter floor. This is in contrast to the characteristics of this breed which include being calm and being easy to handle (The Dorper Sheep Breeders' Society of South Africa, undated). The calm behaviour shown by Merinos is supported by finding reported by Paterson (1990) that polled Merinos are easy to handle than the horned ones.

Most sheep within the three age groups were calm "standing" before stunning (Figure 2a). However, $37 \%$ of Age Group 1 ( $<10$ months) animals were showing signs of panic and were jumping trying to escape. The calm behaviour observed from the older animals compared to the younger ones was expected. Older animals are well experienced with exposure to different situations and are likely to respond better to stressful changes. In a study by Viérin \& Bouissou (2003), older lambs (5 - 6 months) were less fearful than younger lambs (3 - 4 months).
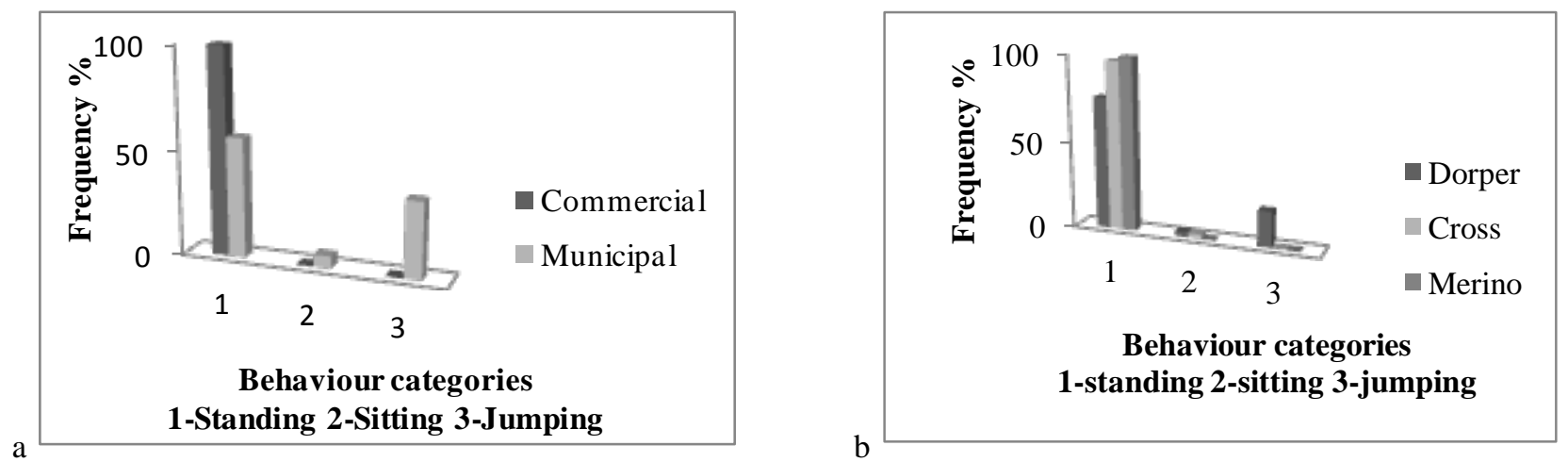

Figure 1 Association frequencies between abattoir type, breed and the animal avoidance-related behaviour before stunning.

In Figure 2b, most ewes (95\%) were calm as compared to the $81 \%$ castrates that demonstrated a panicking/aggressive behaviour. This was expected because generally the male animals are associated with aggression while their female counterparts do not often engage in combative behaviour, except when competing for limited resources (Dweyer, 2009). However in some studies (arena tests) rams appeared less fearful compared to ewes, with ewes being more active having higher measurements of locomotion (Dodd et al., 2012).

Bleeding times differed $(P<0.001)$ with abattoir type and age classes (Table 2$)$. The abattoir type effect on the bleeding times was as expected and can be attributed to the different procedures used at the two abattoirs.

Animals from the MA took longer (74.2 $\pm 2.11 \mathrm{~s})$ to bleed than those from the EL $(61 \pm 1.16 \mathrm{~s})$. According to RMAA (2011), that horizontal bleeding promotes faster bleeding rates. The manual procedures used at the MA from introducing the animals to the slaughter floor may have caused the blood to heat up resulting in veins/ blood arteries relaxing thus blood gushing out when an incision was done. Bleeding times did not differ ( $\mathrm{P}>0.05)$ with breed and the sex of the sheep. On the other hand, older sheep ( $>12$ months) had longer bleeding times (67.5 $\pm 1.82 \mathrm{~s})$ than younger ( $<10$ months) animals (61.6 $\pm 2.64 \mathrm{~s})$. 

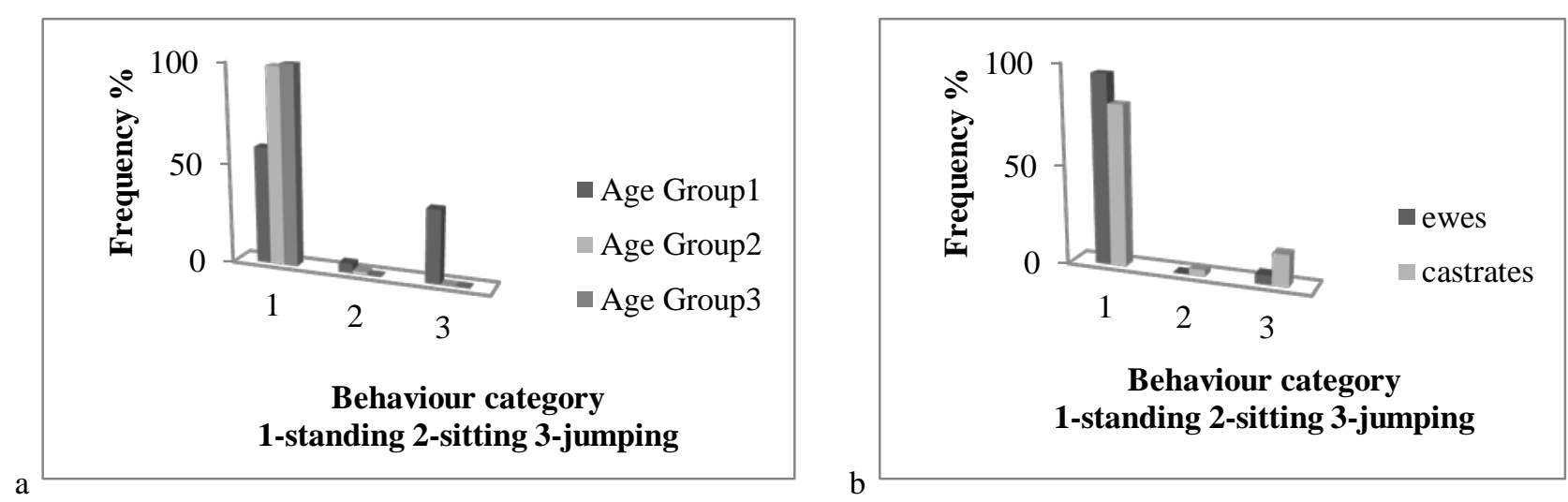

Figure 2 Association between age group, sex and animal avoidance-related behaviour before stunning.

Table 2 The effect of abattoir type, age group, breed, and sex on bleeding time scores of animals at slaughter

\begin{tabular}{lllc}
\hline Factor variables & Factors & Mean $( \pm$ SE) & Significance levels \\
\hline \multirow{2}{*}{ Abattoir Type } & Municipal & $74.2^{\mathrm{a}} \pm 2.11$ & $* *$ \\
& Commercial & $61.0^{\mathrm{b}} \pm 1.16$ & $* *$ \\
Age Group & $1(<10$ months $)$ & $61.6^{\mathrm{b}} \pm 2.64$ & \\
& 2 (11-12 months) & $64.1^{\mathrm{ab}} \pm 2.60$ & \\
& 3 ( $>12$ months $)$ & $67.5^{\mathrm{a}} \pm 1.82$ &
\end{tabular}

${ }^{\text {ab }}$ Means in the same column with different superscripts are significantly different at $P<0.001$.

Figure 3 shows interactions within the breed types (a) and sex (b) of the two abattoirs. Animals slaughtered at MA had longer bleeding rates than those of E.L. Within each sex, sheep slaughtered at the MA took longer to bleed than the ones slaughtered at EL.
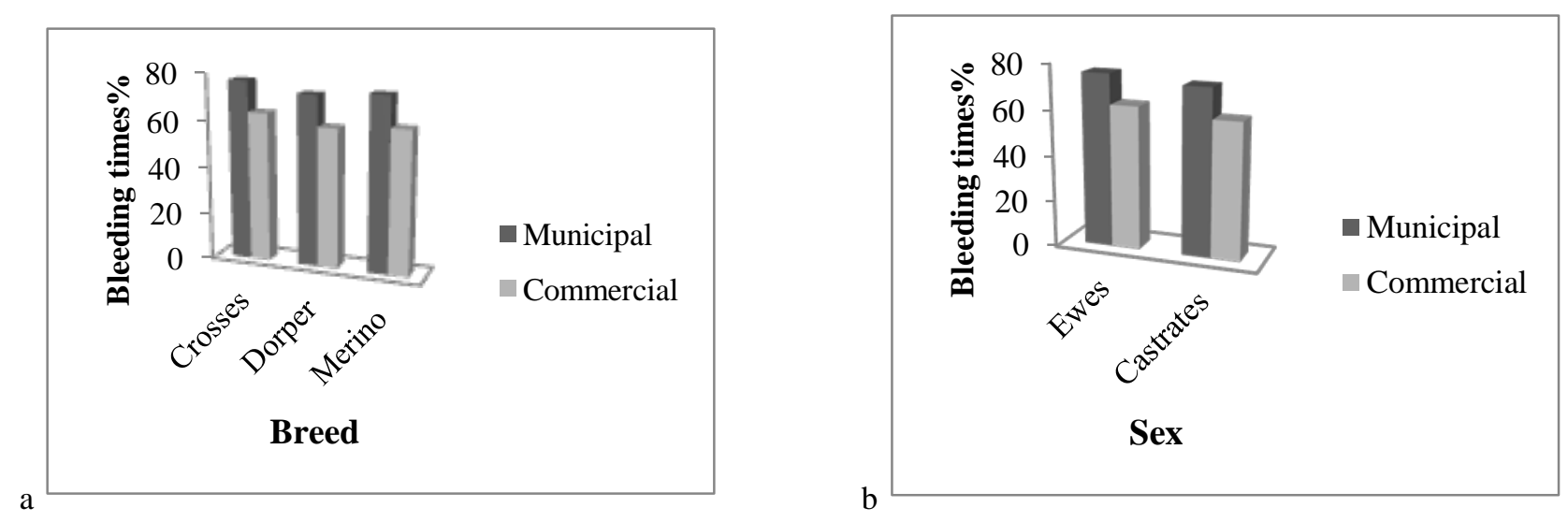

Figure 3 Interactions between the abattoir type; breed (a) and sex (b) of the animals, respectively.

\section{Conclusions and Recommendations}

Different operating procedures at abattoirs bring about different response behaviours in sheep at slaughter and bleeding times at exsanguination. Abattoir type, age, breed and sex affect sheep behaviour at slaughter. Only abattoir type and sex affected bleeding times. 
The abattoir labourers especially for the municipal abattoir require training on the importance of animal welfare issues and how they in turn affect production. These types of abattoirs can also be encouraged to upgrade to the high throughput "commercial” abattoir as this will not only meet the industry requirements but also profit the abattoirs by reducing any possible losses due to improper handling, or poor machinery usage. A more detailed study should be carried out to give descriptive and quality output.

\section{Acknowledgements}

The study was attached to the Red Meat Research and Development Trust (Meat Industry Trust) and the NRF-RMRDT THRIP Project (T113). The authors also thank the participating abattoirs and butcheries.

\section{References}

Boivin, X., Nowak, R., Le Neindre, P., Tournadre, H. \& Le Neindre, P., 1997. Discrimination between shepherds by lambs reared under artificial conditions. J. Anim. Sci. 75, 2892-2898.

Bourguet, C., Deiss, V., Tannugi, C.C. \& Terlouw, E.M.C., 2011. Behavioural and physiological reactions of cattle in a commercial abattoir: Relationships with organisational aspects of the abattoir and animal characteristics. Meat Sci. 88, 158-168.

Broom, D.M. \& Fraser, A.F., 2007. Domestic Animal Behaviour and Welfare. $4^{\text {th }}$ ed. CAB International, UK.

Dodd, C.L., Pitchford, W.S., Edwards, J.E.H. \& Hazel, S.J., 2012. Measures of behavioural reactivity and their relationships with production traits in sheep: A review. Appl. Anim. Behav. Sci. 140, 1-15.

Dodzi, M.S. \& Muchenje, V., 2011. Avoidance-related behavioural variables and their relationship to milk yield in pasture-based dairy cows. Appl. Anim. Behav. Sci. 133, 11-17.

Dorper Sheep Breeders' Society of South Africa provided by Henry du Plooy, Kiewietskloof, Griekwastad 8365, Northern Cape, South Africa. www.ansi.okstate.edu. Accessed on the $22^{\text {nd }}$ February 2012.

Dweyer, C., 2009. The Behaviour of Sheep and Goats. The Ethology of Domestic Animals, 2nd Ed.: An Introductory Text. Ed. Jensen, P., 12, 161-176.

Genstat Discovery Edition, 2008. GenStat Release 7.22 DE (PC/Windows), VSN International Ltd. Used on the 30 June-05 July.

Gonyou, H.W., 1997. Sheep and Goats. Eds Reynnells, R.D. \& Eastwood, B.R., Animal Welfare Issues Compendium. pp. 118-124.

Grandin, T., 1999. Behavioral Principles of Handling Livestock - update. Professional Animal Scientist, Dec. 1989. pp. 1-11.

Grandin, T., 2006. Progress and challenges in animal handling and slaughter in the U.S. Sentience in Animals. Appl. Anim. Behav. Sci., 100, 129-139.

Gregory, N.G., 2005. Recent concerns about stunning and slaughter. Meat Sci. 70, 481-491.

Hansen, I., Cristiansen F., Hansen H.S., Braastad B. \& Bakken M., 2001 Variation in behaviour response of ewes towards predator-related stimuli. Appl. Anim. Behav. Sci. 70, 227-237.

Kirton, A.H. \& Woods, E.G., 1977. Blood weights, bleeding times of electrically stunned sheep slaughter by three different procedures. N. Z. J. Agric. Res. 20, 441-451.

Knowles, T.G., 1998. A review of road transport of slaughter sheep. Vet. Rec. 143, 212-19.

Ndou, S.P., Muchenje, V. \& Chimonyo, M., 2011. Assessment and implications of animal welfare in beef production systems in developing countries. Afr. J. Biotechnol. 10, 1049-1064.

Paterson, M., 1990. National Merino Review. West Perth, Australia: Farmgate Press. pp. 12-17. ISSN 10335811.

Red Meat Abattoir Association (RMAA), 2011. Animal handling practical guidelines for abattoirs. Accessed on 21 January 2012.

Terlouw, E.M.C. \& Porcher, J., 2005. Repeated handling of pigs during rearing. I. Refusal of contact by the handler and reactivity to familiar and unfamiliar humans. J. Anim. Sci. 83, 1653-1663.

Viérin, M. \& Bouissou, M.F., 2003. Responses of weaned lambs to fear eliciting situations: origin of individual differences. Dev. Psychobiol. 42, 131-147. 